\title{
The effects of caffeic acid phenethyl ester on streptozotocin- -induced diabetic liver injury
}

\author{
Taslidere $\mathrm{E}^{1}$, Gul $\mathrm{M}^{2}$, Elbe $\mathrm{H}^{3}$, Cetin $\mathrm{A}^{2}$, Vardi $\mathrm{N}^{2}$, Ozyalin $\mathrm{F}^{4}$, Turkoz $\mathrm{Y}^{4}$ \\ Department of Histology and Embryology, Medical Faculty, Bezmialem Vakif University, \\ Istanbul, Turkey. eliftaslidere@hotmail.com
}

\begin{abstract}
The aim of the present study was to clarify the role of oxidative stress in streptozotocin induced liver injury and the possible protective effect of caffeic acid phenethyl ester (CAPE) using histological and biochemical parameters. 32 male Wistar rats were divided into 4 groups as follows: Group 1: Control animals, Group 2: Control animals given CAPE Group 3: STZ-induced diabetic animals (DM group), Group 4: STZ-induced diabetic rats given CAPE (DM+CAPE group). All the injections started on the same day of single-dose STZ injection and continued for 20 days. At the end of this period, livers were removed and processed for routine histological procedures. Biochemical parameters and morphological changes were examined. In DM group, blood glucose levels were significantly increased compared with the control group. Significant increases in tissue malondialdehyde (MDA) level and decreases in superoxide dismutase (SOD) and total glutathione (GSH) activities were detected in DM group. Administration of CAPE significantly reduced these values. STZ-induced histopathological alterations including inflammatory cell infiltration around portal triad, congestion, loss of glycogen in the hepatocytes. Additionally, degenerative cellular alterations, such as numerous vacuolizations including myelinic figure formation, pyknotic nuclei with peripheral localization of heterochromatin condensation and mitochondrial elongation were observed in cytoplasm of hepatocytes. CAPE significantly reduced these histopathological changes. Our results indicate that CAPE should be considered in the prevention of oxidative stress in diabetic liver (Tab. 3, Fig. 4, Ref. 47). Text in PDF www.elis.sk. KEY WORDS: caffeic acid phenethyl ester, streptozotocin, liver.
\end{abstract}

\section{Introduction}

Diabetes mellitus is a group of metabolic disorders with different underlying aetiologies, each characterized by hyperglycemia due to underutilization and/or over production of glucose (1). Hyperglycemia may cause oxidative stress, which in turn may result in cellular tissue damage $(2,3)$. Streptozotocin (STZ) is an established diabetogenic agent in animal models, which induces insulin deficiency due to its selective pancreatic $\beta$-cell cytotoxicity caused by DNA alkylation and nitric oxide (NO) generation $(4,5)$. By affecting glycogen and lipid metabolism, diabetes causes structural and functional abnormalities in the liver (6). Studies have shown that hepatobiliary disorders, such as inflammation, necrosis and acute liver failure can follow diabetes $(7,8)$.

Higher glucose levels increase the production of free radicals and serum concentration of malondialdehyde and conjugated dienes which are markers of cellular damage due to free radicals (9).

${ }^{1}$ Department of Histology and Embryology, Medical Faculty, Bezmialem Vakif University, Istanbul, Turkey, ${ }^{2}$ Department of Histology and Embryology, Medical Faculty, Inonu University, Malatya, Turkey, ${ }^{3}$ Department of Histology and Embriyology, Medical Faculty, Mugla Sitki Kocman University, Mugla, Turkey, and ${ }^{4}$ Department of Biochemistry, Inonu University Medical Faculty, Malatya, Turkey

Address for correspondence: E. Taslidere, MD, Bezmialem Vakif University, Faculty of Medicine Department of Histology and Embryology, 34093 Istanbul, Turkey.

Phone: +90.505 .6680494$
Oxidative stress is an imbalance between the production of free radicals and defence capacity of antioxidants. Oxidative stress is measured by indices of lipid peroxidation (LPO) such as malondialdehyde (MDA), antioxidant enzymes including superoxide dismutase (SOD) and glutathione-S-transferases (GSTs) (10). Oxidative stress has been documented in hyperglycemia of both type 1 and type 2 diabetes and thus should be regarded as central player in the development of diabetes complications (3). This notion has been supported by several studies utilizing both diabetic human and animal models $(11,12)$.

Caffeic acid (3,4-dihydroxycinnamic acid) phenethyl ester (CAPE) is an active component of honeybee propolis extracts and has been used for many years as a folk medicine. It has anti-inflammatory, immunomodulatory, antiproliferative and antioxidant properties and has been shown to inhibit lipo-oxygenase activities as well as to suppress lipid peroxidation $(13,14)$.

This experimental study was designed to clarify the role of oxidative stress in STZ induced liver injury and the possible protective effect of CAPE using histological and biochemical parameters.

\section{Material and methods}

Chemicals. STZ and CAPE were purchased from Pharmacia Company (Sigma, St. Louis, MO).

Animals. 32 Wistar albino male rats were housed in an air-conditioned room with 12-h light and dark cycles, where the tem- 
perature $\left(22 \pm 2{ }^{\circ} \mathrm{C}\right)$ and relative humidity $(65-70 \%)$ were kept constant. All experimental protocols were approved by the Inonu University, School of Medicine Animal Care and Use Committee, Malatya, Turkey.

Experimental Protocol. The Rats were divided into 4 groups randomly, each group including 8 animals.

Group 1: Control animals

Group 2: Control animals given CAPE

Group 3: STZ-induced diabetic animals (DM group)

Group 4: STZ-induced diabetic rats given CAPE (DM+CAPE group)

Experimental animals were rendered diabetic by an intraperitoneal injection of a single dose STZ $(55 \mathrm{mg} / \mathrm{kg})$ dissolved in physiological saline $(0.9 \% \mathrm{NaCl})(\mathrm{PS})$. CAPE $(10 \mu \mathrm{mol} / \mathrm{kg})$ was given by ip to rats for 20 days after the experimental animals were made diabetic. The plasma glucose level was measured; at the start of experiment, 72 hours after administration of injection STZ and after 20 days to ascertain diabetic status of the animals using glucometer. At the end of the 21 st day, all the rats were sacrificed with ketamine/xylazine anesthesia; their liver tissues were excised.

\section{Histological assessment}

The livers of rats were rapidly removed at the end of the experiment and divided to three portions. The first part of the samples were placed in $10 \%$ buffered formalin and prepared for routine parafin embedding. Tissue sections were cut at $5 \mu \mathrm{m}$, mounted on slides, stained with hematoxylineosin (H-E) for general liver structure, periodic acid schiff (PAS) to demonstrate the glycogen deposition in hepatocytes and toluidin blue to determine the number of mast cells. The sections were examined by a Leica DFC 280 light microscope by a histologists unaware of the status of animals. The liver damage severity was semiquantitatively assessed as follows; mononuclear cell infiltration, congestion and loss of the glycogen deposition in hepatocytes. Microscopic damage was identified as absent (0), slight (1), moderate (2), and severe (3), for each criterion. Mast cells were counted in the 10 microscopic under 40X objective magnification using Leica Q Win Image Analysis System (Leica Micros Imaging Solution Ltd. Cambridge, UK). The other parts of the tissues were processed for electron microscopic examination. For that purpose, samples were fixed in $2.5 \%$ glutaraldehyde buffered with $0.2 \mathrm{M} \mathrm{NaH}_{2} \mathrm{PO}_{4}+\mathrm{NaHPO}_{4}$ $(\mathrm{pH}=7.2-7.3)$ and postfixed in $1 \% \mathrm{OsO} 4$. After dehydration in acetone, they were embedded in Araldite CY 212. Ultrathin sections were stained with uranyl acetate and lead citrate and than were examined in a Zeiss Libra 120 electron microscope. The other part was placed in liquid nitrogen and stored at $-70{ }^{\circ} \mathrm{C}$ until assay for malondialdehyde (MDA), reduced glutathione (GSH), and superoxide dismutase (SOD).

\section{Biochemical assessment}

The remaining parts of the samples were homogenized in ice-cold 0.1 M Tris-HCI buffer (pH 7.5) (containing protease inhibitor, phenylmethlsulfonyl fluoride, $1 \mathrm{mM}$ ) with a homogenizer (IKA ultra turrax T25 basic) at 16.000 r.p.m. for $2 \mathrm{~min}$ at $+4-8^{\circ} \mathrm{C}$.

\section{Measurement of tissue MDA}

MDA equivalents in the liver tissue homogenate were determined by the method of Mihara and Uchiyama (15). Half a milliliter of homogenate was mixed with $3 \mathrm{~mL} \mathrm{H} 3 \mathrm{PO} 4$ solution ( $1 \%$ w/v), $1 \mathrm{~mL}$ thiobarbituric acid solution $(0.67 \% \mathrm{w} / \mathrm{v})$ was added and the mixture was heated in a water bath for $45 \mathrm{~min}$ at $95^{\circ} \mathrm{C}$. The colored complex that was formed was extracted with n-butanol and the absorbance at $532 \mathrm{~nm}$ was measured. Tetramethoxypropane was used as a standard. The amounts of lipid peroxides were calculated and are reported as nmol/mg protein.

\section{Measurement of total glutathione}

The formation of 5-thio-2-nitrobenzoate (TNB) was followed spectrophotometrically at $412 \mathrm{~nm}$ (16). The amount of GSH in the extract was determined in $\mathrm{nmol} / \mathrm{mg}$ protein utilizing a commercial GSH as the standard.

\section{Measurement of tissue SOD}

Superoxide dismutase (SOD; copper, zinc- SOD) activity was measured in the supernatant fraction using xanthine oxidase/ cytochrome $\mathrm{c}$ method according to the method followed by McCord and Fridovich (17) where one unit of activity is the amount of enzyme needed to cause half-maximal inhibition of cytochrome $\mathrm{C}$ reduction. The amount of SOD in the extract was determined in nanograms of enzyme per milligram protein utilizing a commercial SOD as standard.

\section{Determination of protein levels}

Protein levels of the tissue samples were measured by the Bradford method (18). The absorbance measurement was taken at $595 \mathrm{~nm}$ using a UV-VIS spectrophotometer. Bovine serum albumin (BSA)

\section{Statistical analysis}

A computer program (SPSS 11.0) was used for statistical analysis. The results were compared with Kruskal-Wallis variance analysis. Where differences among the groups were detected, group means were compared using the Mann-Whitney U test. Values of $\mathrm{p}<0.05$ were considered significant. All results were expressed as means \pm standard error (SE). In-group change was evaluated by Wilcoxon's paired matched sample test. Results were considered statistically significant at $\mathrm{p}<0.05$.

\section{Results}

\section{Blood glucose level}

Table 1 shows the levels of blood glucose in control and experimental groups of rats. Prior to induction of diabetes, the blood glucose levels of all groups were similar. After streptozotocin (STZ) injection, a significant increase was observed in the blood glucose levels of diabetic rats at 20th day compared to day 0 ( $\mathrm{p}<$ $0.05)$. CAPE treatment produced significant changes in the blood glucose levels in nondiabetic rats $(\mathrm{p}<0.05)$. The administration of CAPE for 20 days caused a decrease in the level of blood glucose in the diabetic rats. 
Tab. 1. Initial and final blood glucose levels of four groups of eight rats each.

\begin{tabular}{|c|c|c|c|c|}
\hline Parameters & Control & CAPE & DM & $\mathrm{DM}+\mathrm{CAPE}$ \\
\hline Initial blood glucose $(\mathrm{mg} / \mathrm{dl})$ & $111.57 \pm 5.37$ & $96.71 \pm 3.48$ & $438.28 \pm 11.41^{\mathrm{a}}$ & $425.14 \pm 9.00$ \\
\hline Final blood glucose (mg/dl) & $110.14 \pm 4.83$ & $115.14 \pm 8.53$ & $469.85 \pm 26.78^{\mathrm{a}}$ & $352.71 \pm 7.93^{\mathrm{b}}$ \\
\hline
\end{tabular}

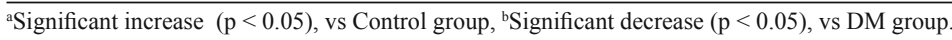
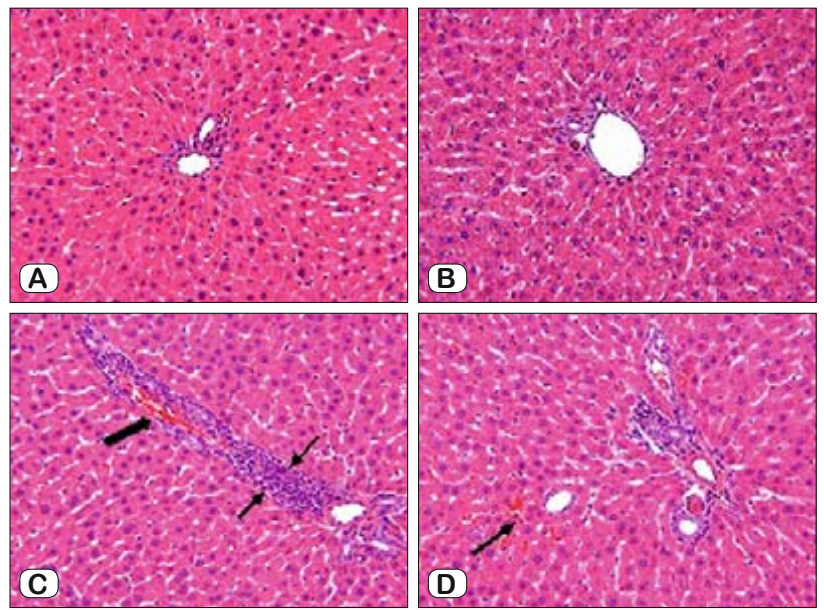

Fig. 1. (A) Control and (B) CAPE groups: the normal hepatocytes architecture (C) DM group: notice cellular infiltration around portal triad (thin arrows) and sinusoidal congestion (thick arrows) (D) DM+CAPE group: the appearance of hepatocytes is almost intact but mild sinusoidal congestion is still precent (arrow) H\&E; x20.
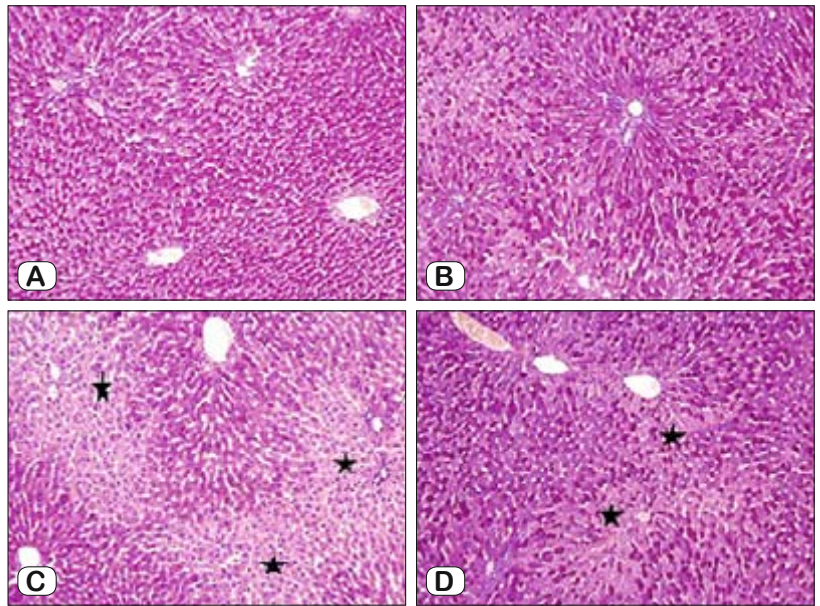

Fig. 2. (A) Control and (B) CAPE group: The PAS-positive reaction shows a magenta staining where glycogen is present within hepatocytes (C) DM group marked reduction in glycogen content especially in the periphery of classic liver lobule (asterisks) (D) DM+CAPE group: the view of glycogen is nearly normal except mild loss of the glycogen in some areas (asterisks) PAS; x10.

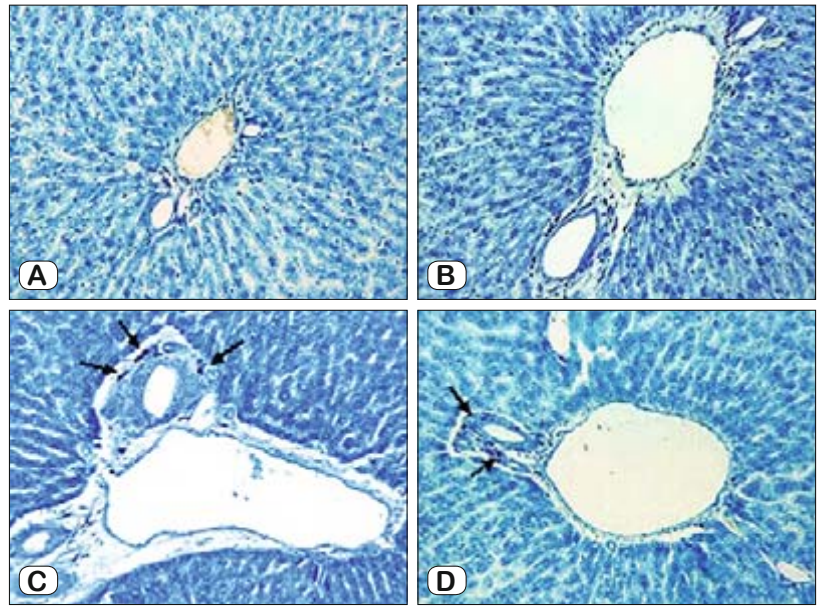

Fig. 3. Control (A) and CAPE (B) groups The view of mast cells. DM group (C) shows a marked increase in the number of mast cells. DM+CAPE group (D) The number of mast cells is decreased compare to DM group (arrows indicate mast cell) MGG; $\mathbf{x 4 0 .}$

\section{Histological results}

Light microscopic evaluation

The control and CAPE groups showed a normal appearance of the liver cells (Fig. 1A, B). However in the DM group, histological alterations were observed such as inflammatory cell infiltration around portal triad (Fig. 1C). In addition, congestion was seen in this group (Fig. 1D). In DM+CAPE group although the liver tissue preserved it's normal histological apperance, congestion still was marked in some area (Fig. 1E).

The PAS-positive reaction shows a magenta staining where glycogen is present within hepatocytes in control and CAPE group (Fig. 2A, B). The glycogen storage in hepatocytes was observed as decreased in the DM group (Fig. 2C). On the other hand, CAPE treatment reduced loss of the glycogen in the hepatocytes (Fig. 2D). Microscopic damage scores are given in Table 2.

Other remarkable finding in the DM group was the increase in the number of mast cell. On the other hand in DM+CAPE group $(34.14 \pm 7.05)$ the number of mast cell was found to be significantly decreased when compared with DM group (49.42 \pm 15.75$)$ $(\mathrm{p}<0.0001)$ (Fig. 3A, B, C, D).

Tab. 2. The results of semiquantitative histological assessment and the number of mast cells in all groups.

\begin{tabular}{|c|c|c|c|c|}
\hline Parameters & Control & CAPE & DM & $\mathrm{DM}+\mathrm{CAPE}$ \\
\hline Histopathological Score & $0.28 \pm 0.48$ & $0.42 \pm 0.53$ & $6.57 \pm 0.53^{\mathrm{a}}$ & $4.14 \pm 0.37^{b}$ \\
\hline Number of mast cells & $14.57 \pm 4.79$ & $21.28 \pm 7.80$ & $49.42 \pm 15.75^{\mathrm{a}}$ & $34.14 \pm 7.05^{\mathrm{b}}$ \\
\hline
\end{tabular}

${ }^{a}$ Significant increase $(p=0.0001)$, vs Control group, ${ }^{b}$ Significant decrease $(p=0.0001)$, vs DM group. 
Tab. 3. The results of biochemical parameters in all groups.

\begin{tabular}{|c|c|c|c|c|}
\hline Parameters & Control & CAPE & $\mathrm{DM}$ & $\mathrm{DM}+\mathrm{CAPE}$ \\
\hline MDA & $270.25 \pm 8,95$ & $249.00 \pm 31.22$ & $339.87 \pm 39.62^{\mathrm{a}}$ & $257.62 \pm 43.81^{b}$ \\
\hline GSH & $3.83 \pm 0.31$ & $3.51 \pm 0.61$ & $3.06 \pm 0.59^{c}$ & $3.75 \pm 0.20^{\mathrm{d}}$ \\
\hline SOD & $118.31 \pm 35.87$ & $129.97 \pm 9.58$ & $68.08 \pm 39.83^{\mathrm{c}}$ & $131.2 \pm 21.16^{\mathrm{d}}$ \\
\hline
\end{tabular}

${ }^{\mathrm{a}}$ Significant increase $(\mathrm{p}=0.0001)$ v. Control group, ${ }^{\mathrm{b}}$ Significant decrease $(\mathrm{p}=0.0001)$ vs DM group

Electron microscopic evaluation

Examination of livers obtained from the control and CAPE groups showed normal ultrastructural appearance (Fig. 4A, B). In the ultrathin sections from livers of DM group, we detected many degenerative alterations in hepatocyte and Kupffer cells, such as numeourus vacuolization including myelinic figures formation, mitochondrial elongation (Fig. 4C), pyknotic nuclei with peripheral localization of heterochromatin condensation. In addition, many lysosomes were present with in the cytoplasm of hepatocytes and Kupffer cells. Also phagocytic bodies were located in the cytoplasm of the hepatocytes in this group (Fig. 4D). Liver sections of CAPE administered rats were nearly normal in ultrastructural appearances. However, intracytoplasmic vacuolization and lysosomes were rarely seen. (Fig. 4E, F).

\section{Biochemical results}

The levels of MDA and GSH and the activities of SOD of the liver tissue are shown in Table 2. In the DM group, MDA levels were increased $(p<0.0001)$. SOD activities and GSH levels were decreased significantly $(p<0.0001)$ when compared with the control group. MDA levels were decreased in the DM+CAPE groups when compared with the DM group $(\mathrm{p}<0.0001)$. GSH level and SOD activities were increased significantly in the DM+CAPE groups when compared with the DM group $(p<0.0001)$. These results indicate that CAPE is effectively able to inhibit lipid peroxidation and the production of MDA, and inhibit the need and usage of antioxidant enzymes and/or stimulate the production of antioxidant enzymes in DM-injured liver.

\section{Discussion}

In this study, we observed histological and biochemical changes in STZ-induced rats, which were alleviated with CAPE treatment. The STZ-induced diabetic rat is one of the animal models of human diabetes mellitus (19). STZ is given as a single injection of $40-60 \mathrm{mg} / \mathrm{kg}$ to provoke diabetes in rats (20-22). We used STZ, an antibiotic produced by Streptomyces achromogenes, at a single dose of $55 \mathrm{mg} / \mathrm{kg}$. This type 1 diabetes mellitus model is characterized by hyperglycemia, hypoinsulinemia, alterations in carbohydrate and lipid metabolism (19). Hyperglycemia is an important factor in the development and progression of the complications of diabetes mellitus and a good glycemic control is necessary to prevent diabetic complications (23).

In our study, increased blood glucose concentration during the experimental period clearly indicated the persistent hyperglycemia in the STZ-induced diabetic rats. The administration of CAPE lowered the blood glucose concentration in diabetic rats. In the
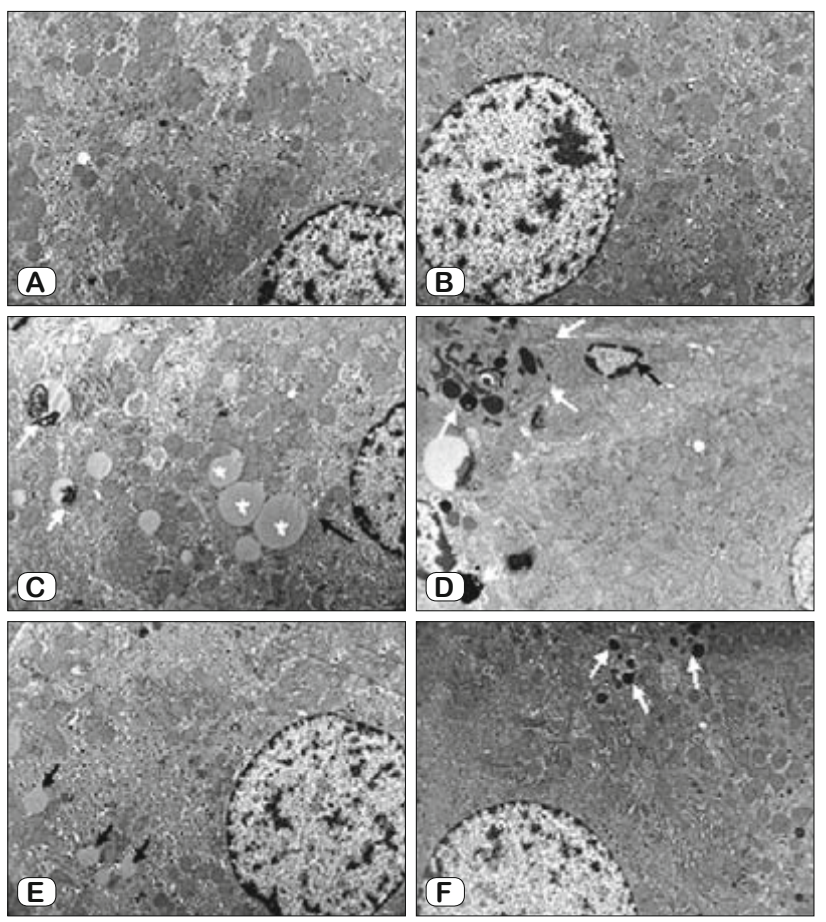

Fig. 4. Control (A) and CAPE (B) view of normal ultrastructural appearance. DM (C) Myelinic figure formation (white arrows), vacuolization (asterisks) and mitochondrial elongation (black arrow) are observed. DM (D) phagocytic bodies (white arrows), pyknotic nuclei with peripheral localization of heterochromatin condensation (black arrows) and lysosomes are seen (arrowhead). DM+CAPE (E, F) Liver sections nearly normal in structural and ultrastructural appearances. However, intracytoplasmic vacuolization (black arrows) and lysosomes (white arrows) are rarely seen. Uranyl acetate and lead citrate; x6300.

previous studies, it was shown that blood glucose concentration was decreased by using CAPE (24).

Caffeic acid phenethyl ester (CAPE), a flavonoid-like compound, is one of the major components of honeybee propolis. CAPE has no possible harmful effects on normal cells but several biological and pharmacological properties including antioxidant, anti-inflammatory, anti-carcinogenic, antiviral and immunomodulatory activities. At a concentration of $10 \mu \mathrm{M}$, CAPE completely blocks the production of reactive oxygen species in human neutrophils and the xanthine/xanthine oxidase system $(13,25)$. The levels of lipid peroxidation and the activities of antioxidant enzymes increase in streptozotocin (STZ)-induced diabetic rats. CAPE was shown to inhibit lipooxygenase activities and suppress lipid peroxidation $(14,27)$.

Liver is regarded as one of the central metabolic organs in the body which regulates and maintains homeostasis. It performs 


\section{6-282}

most of the reactions involved in the synthesis and utilization of glucose. The balance between glucose production and its utilization in the liver is regulated primarily by insulin. In experimental diabetes, glucose metabolism is remarkably altered. Persistent hyperglycemia is a major contributor to metabolic alterations in the pathogenesis of diabetic complications, especially neuropathy and microvascular disease (36).

This study investigates whether CAPE has protective effects on the STZ-induced liver damage. Hepatocellular damage developed in the liver after STZ administration in rats has been shown by several authors $(10,30)$. Vardi et al have reported deterioration in the radial placement of hepatocytes starting from the central veins towards the periphery in the liver and hydropic change in hepatocytes located at the periphery of the lobules (30). Hamadi et al have given an account of STZ, administered as a single dose (60 $\mathrm{mg} / \mathrm{kg}$ ), generating inflammation, necrosis in the liver of diabetic rats and vacuolisation in hepatocytes (10). In this study, histological examinations of liver tissues in DM group of rats showed severe histological changes such as mononuclear cell infiltration, hemorrahage and loss of the glycogen deposition in hepatocytes. The glycogen content in hepatocyte cytoplasm was evaluated via PAS staining method in our study. A significant loss of glycogen was observed in the periphery of the hepatic lobules of the STZadministered groups through this method. Glycogen, which is the main energy source of hepatocytes, is also an important parameter indicating the liver damage.

Loss of glycogen stores in the cells is attributed to the dependence of the cell on glucose because of the deterioration of energy metabolism (31). Ros et al reported that STZ treatment caused a significant decrease in the liver glycogen content (32). Another finding extracted from our study was the change in the number of mast cells after STZ administration. The number of mast cells located in the portal areas significantly increased after STZ administration. Mast cells are recognized as active participants in mediating a wide range of reactions including autoimmunity, inflammation and infection. Mast cells are tissuespecific and respond to different stimulants in different tissues (33). Mast cells function by producing secretory granules that release an assortment of bioactive molecules including cytokines, chemokines and proteases as chymase and tryptase, into the surrounding tissues, leading to tissue remodelling. Mast cells are sensitive to many environmental stressors and to those specific to diabetes $(34,35)$.

In our study, histopathological changes in the liver were significantly improved in the CAPE treatment group. Moreover, we provided many clues about the cytoprotective effect of CAPE by examining hepatocytes by transmission electron microscope. We detected many degenerative cellular alterations, such as numerous vacuolizations including myelinic figure formation, pyknotic nuclei with peripheral localization of heterochromatin condensation and mitochondrial elongation. Mitochondria are highly dynamic organelles that mediate essential cell functions such as apoptosis and cell-cycle control in addition to their role as efficient ATP generators. Changes in mitochondrial morphology are firmly regulated and their shape can shift between small, fragmented units and larger networks of elongated mitochondria (36). We demonstrated that mitochondrial elements elongated after STZ-induced liver injury. In addition, many lysosomes were present within the cytoplasm of hepatocytes and Kupffer cells. Increased lysosome level is also an indicator of the cell injury. Administration of CAPE resulted in a prominent decrease in lysosomal content of the hepatocytes.

In the present study, administration of STZ caused an increase in the lipid peroxidation and decreased the levels of nonenzymatic antioxidants such as SOD and GSH in diabetic rats when compared to normal rats. Decreases in non-enzymatic antioxidants levels might be due to their increased utilization for scavenging free radicals. These findings are in accordance with the previous studies on diabetic animal models $(28,37-39)$. Experimental results have indicated that LPO played a role in tissue injury in STZ-induced diabetic rats $(40,41)$. The level of MDA, an end- product of LPO, significantly increased in the liver of the untreated diabetic rats. Thus, increased MDA level in diabetes mellitus suggests that hyperglycaemia induces peroxidative reactions in lipids (42). Besides, it has been reported that diabetes increased oxidative stress in many organs, especially in the liver (29). Subsequently increased MDA levels were in concordance with the results of the previous studies on liver $(43,44)$. CAPE is a potent antioxidant, which has been reported to prevent oxidative injury secondary to peroxidation (45). In experimental studies, it has been shown that CAPE protects STZ-induced liver injury $(28,46)$.

Within the cell, the reactive oxygen species (ROS) is regulated by antioxidant defense system consisting of non-enzymatic GSH and enzymatic SOD antioxidants (47). We found significant decreases in the mean tissue SOD activities and GSH levels in the DM group compared to the controls. CAPE has been shown to stimulate several anti-oxidative enzymes, such as SOD and GSH which increase the efficiency of CAPE as an antioxidant.

It can be concluded that diabetes mellitus increases oxidative stress in hepatic tissue. CAPE inhibits LPO and regulates antioxidant enzymes of diabetic rat liver. The protective role of CAPE might be related with its antioxidant property. The present results suggest that CAPE should be considered in the prevention of oxidative stress in diabetic liver.

\section{References}

1. Greenberg RA, Sacks DB. Screening for diabetes: is it warranted? Clin Chim Acta 2002; 315: 61-69.

2. Kuyvenhoven JP, Meinders AE. Oxidative stress and diabetic mellitus pathogenesis of long-term complications. Eur J Internat Med 1999; 10: 9-19.

3. West IC. Radicals and oxidative stress in diabetes. Diabet Med 2000;17: 171-180.

4. Harb G, Toreson J, Dufour J et al. Acute exposure to streptozotocin but not human proinflammatory cytokines impairs neonatal porcine islet insulin secretion in vitro but not in vivo. Xenotransplantation 2007; 14 (6): 580-590. 
5. Konrad RJ, Mikolaenko I, Tolar JF, Liu K et al. The potential mechanism of the diabetogenic action of streptozotocin: inhibition of pancreatic beta-cell O-GlcNAc-selective N-acetyl-beta-D-glucosaminidase. Biochem J 2001; 356: 31-41.

6. Sanchez SS, Abregú AV, Aybar MJ et al. Changes in liver gangliosides in streptozotocin induced diabetic rats. Cell Biol Int 2000; 24: 897-904.

7. Latry P, Bioulac-Sage P, Echinard E et al. Perisinusoidal fibrosis and basement membrane-like material in the livers of diabetic patients. Hum Pathol 1987; 18: 775-780.

8. Tolman KG, Fonseca V, Tan MH et al. Narrative review: hepatobiliary disease in type 2 diabetes mellitus. Ann Intern Med 2004; 141: 946-596.

9. Curcio F, Pegoraro I, Dello Russo P et al. Sod and GSH inhibit the high glucose-induced oxidative damage and the PDGF increased secretion in cultured human endothelial cells. Thromb Haemost 1995; 74 (3): 969-973.

10. Hamadi N, Mansour A, Hassan MH et al. Ameliorative effects of resveratrol on liver injury in streptozotocin induced diabetic rats. J Biochem Mol Toxicol 2012; 26 (10): 384-392.

11. Ohkuwa T, Sato Y, Naoi M. Hydroxyl radical formation in diabetic rats induced by streptozotocin. Life Sci 1995; 56: 1789-1798.

12. Park KS, Kim JH, Kim MS et al. Effects of insülin and antioxidant on plasma 8-hydroxyguanine and tissue 8-hydroxydeoxyguanosine in streptozotocin-induced diabetic rats. Diabetes 2001; 50: 2837-2841.

13. Sud'ina GF, Mirzoeva OK, Pushkareva GA et al. Caffeic acid phenethyl ester as a lipoxygenase inhibitor with antioxidant properties. FEBS Lett 1993; 329: 21-24.

14. Michaluart P, Masferrer JL, Carothers AM et al. Inhibitory effects of caffeic acid phenethyl ester on the activity and expression of cyclooxygenase-2 in human oral epithelial cells and in a rat model of inflammation. Cancer Res 1999; 59: 2347-2352.

15. Uchiyama, M. Mihara M. Determination of MDA precursor in tissue by TBA test. Anal Biochem 1978; 36: 271-278.

16. Elman GL. Tissue sulphydryl groups. Arch Biochem Biophys 1979; 95: 351-358.

17. McCord JM, Fridovich I. Superoxide Dismutase. An Enzymic Function for Erythrocuprein (Hemocuprein). J Biol Chem 1969; 244: 60496055 .

18. Bradford MM. A Rapid and Sensitive Method for the Quantitation of Microgram Quantities of Protein Utilizing the Principle of Protein-Dye Binding. Anal Biochem 1976; 72: 248-254.

19. Gao LH, Liu WP, Wang BL et al. Effects of bis (a-furancarboxylato) oxovanadium (IV) on non-diabetic and streptozotocin-diabetic rats. Clin Chim Acta 2006; 368: 173-178.

20. Maiti R, Janav D, Das UK. Antidiabetic effect of aqueous extract of seed of Tamarindus indica in streptozotocin-induced diabetic rats. J Ethnopharm 2004; 92: 85-91.

21. Elbe H, Vardi N, Esrefoglu M et al. Amelioration of streptozotocininduced diabetic nephropathy by melatonin, quercetin, and resveratrol in rats. 2014 doi: 10.1177/0960327114531995

22. Taslidere E, Vardi N, Orman D et al. Anti-Apoptotic Effects of Aminoguanidine Against Liver Damage on Experimental Diabetes in Rats. J Turgut Ozal Med Cent 2014: 21 (2): 111-117.
23. Arun N, Nalini N. Efficacy of turmeric on blood sugar and polyol pathway in diabetic albino rats. Plants Foods Hum Nutr 2002; 57: 41-52.

24. Fuliang HU, Hepburn HR, Xuan $\mathbf{H}$ et al. Effects of propolis on blood glucose, blood lipid and free radicals in rats with diabetes mellitus. Pharmacol Res 2005; 51 (2): 147-152.

25. Rao C, Desai D, Kaul B et al. Effect of caffeic acid esters on carcinogen-induced mutagenicity and human colon adenocarcinoma cell growth. Chem Biol Interact 1992; 84: 277-290.

26. Yilmaz HR, Uz E, Yucel $\mathbf{N}$ et al. Protective effect of caffeic acid phenethyl ester (CAPE) on lipid peroxidation and antioxidant enzymes in diabetic rat liver. J Biochem Mol Toxicol 2004; 18: 234-238.

27. Aksoy N, Vural H, Sabuncu T et al. Effects of melatonin on oxidativeantioxidative status of tissues in streptozotocin-induced diabetic rats. Cell Biochem Funct 2003; 21: 121-125.

28. Gupta D, Raju J, Prakash JR et al. Changes in the lipid profile, lipogenic and related enzymes in the livers of experimental diabetic rats: Effect of insulin and vanadate. Diabetes Res Clin Pract 1999; 46: 1-7.

29. Sochor M, Baquer NZ, Mclean P. Glucose over and underutilization in diabetes: Comperative studies on the change in activities of enyzmes of glucose metabolism in rat kidney and liver. Mol Physiol 1985; 7: 51-68.

30. Vardi N, Iraz M, Öztürk F et al. Deneysel diyabetin siçan karaciğerinde meydana getirdiği histolojik değisiklikler üzerine melatoninin iyilestirici etkileri. Turkiye Klinikleri J Med Sci 2007; 27: 641-648.

31. Abdel Salam OM, Baiuomy AR, El-Shenawy SM et al. Effect of Pentoxifylline on Hepatic Injury Caused in the Rat by the Administration of Carbon Tetrachloride or Acetaminophen. Pharmacol Rep 2005; 57 (5): 596-603.

32. Ros S, García-Rocha M, Calbó J. Restoration of hepatic glycogen deposition reduces hyperglycaemia, hyperphagia and gluconeogenic enzymes in a streptozotocin-induced model of diabetes in rats. Diabetologia 2011; 54 (10): 2639-2648.

33. Caughey GH. Mast cell tryptases and chymases in inflammation and host defense. Immunol Rev 2007; 217: 141-154.

34. Sick E, Brehin S, Andre $\mathbf{P}$ et al. Advanced glycation end products (AGEs) activate mast cells. Br J Pharmacol 2010; 161: 442-455.

35. Huang ZG, Jin Q, Fan $\mathbf{M}$ et al. Myocardial remodeling in diabetic cardiomyopathy associated with cardiac mast cell activation. PLoS ONE 2013; 8 (3).

36. Rambold AS, Kostelecky B, Lippincott-Schwartz J. Together we are stronger: fusion protects mitochondria from autophagosomal degradation. Autophagy 2011; 7 (12): 1568-1569.

37. Olukman M, Sezer ED, Ulker $S$ et al. Fenofibrate treatment enhances antioxidant status and attenuates endothelial dysfunction in streptozotocin-induced diabetic rats. Exp Diabet 2010; 2010: 10. doi: $10.1155 / 2010 / 828531$.

38. Mahesh T, Menom VP. Quercetin alleviates oxidative stress in streptozotocin-induced diabetic rats. Phytother Res 2004; 18: 123-127.

39. Thirunavukkarasu M, Penumathsa SV, Koneru S et al. Resveratrol alleviates cardiac dysfunction in streptozotocininduced diabetes: role of nitric oxide, thioredoxin, and heme oxygenase. Free Radic Biol Med 2007; 43: 720-729.

40. Pari L, Latha M. Antidiabetic effect of Scoparia dulcis: Effect of lipid peroxidation in streptozotocin diabetes. Gen Physiol Biophys 2005; 24: 13-26. 


\section{6-282}

41. Rajasekaran S, Sivagnanam K, Subramanian S. Antioxidant effect of Aloe vera gel extract in streptozotocin-induced diabetes in rats. Pharmacol Rep 2005; 57: 90-96.

42. Hunkar T, Aktan F, Ceylan A et al. Effects of cod liver oil on tissue antioxidant pathways in normal and streptozotocin-diabetic rats. Cell Biochem Funct 2002; 20: 297-302.

43. Gezginci-Oktayoglu S, Basaraner $\mathbf{H}$, Yanardag $\mathbf{R}$ et al. The effects of combined treatment of antioxidants on the liver injury in STZ diabetic rats. Dig Dis Sci 2009; 54 (3): 538-546. doi: 10.1007/s10620-008-0381-0.

44. Guven A, Yavuz O, Cam M et al. Effects of melatonin on streptozotocin-induced diabetic liver injury in rats. Acta Histochem 2006; 108 (2): 85-93.
45. Durmus M, H. Yilmaz H.R, Uz E et al. The Effect of Caffeic Acid Phenethyl Ester (CAPE) Treatment on Levels of MDA, NO and Antioxidant Enzyme Activities in Retinas of Streptozotocin-Induced Diabetic Rats. Turk J Med Sci 2008; 38 (6): 525-530.

46. Zhu W, Li YH, Chen ML et al. Protective effects of Chinese and Brazilian propolis treatment against hepatorenal lesion in diabetic rats. Hum Exp Toxicol 2011; 30 (9): 1246-1255.

47. Maritim AC, Sanders RA, Watkins JB. Diabetes, Oxidative Stress, and Antioxidants: A Review. J Biochem Mol Toxic 2003; 17: 24-38.

Received August 21, 2015. Accepted August 31, 2015. 